\title{
A review of wound management materials
}

\begin{abstract}
Wound dressing is one of the main external effectors during the healing process of wounds. The following characteristics are required for ideal modern and smart wound dressings; bioadhesiveness to the wound surface, ease of applications, easily sterilised, inhibition of bacterial invasion, biodegradability, oxygen permeability, nontoxic, etc. There is a growing concern about the usage of smart materials as wound dressings. These are natural polymers such as polysaccharides and derivatives (e.g., carboxymethlycellulose, alginates, chitosan and heparin), proteoglycans and proteins (e.g., collagen, gelatine, fibrin, and keratin), and what is more, the impact of such materials on the wound healing process is still under investigation by scientists and experts in general. Development of wound dressing materials is main objectives of this paper which will provide general information on future wound dressing materials.
\end{abstract}

Keywords: wound dressings, nonwovens, carboxyl methylcellulose, cmc, alginate fibres

\author{
Volume 4 Issue I - 2018
}

\author{
Muhammet Uzun \\ Department of Textile Engineering, Faculty of Technology, \\ Marmara University, Turkey
}

\begin{abstract}
Correspondence: Muhammet Uzun, Department of Textile Engineering, Faculty of Technology, Marmara University, Kadiköy, Istanbul, 34722, Republic of Turkey, Tel 9053645 19462,
\end{abstract} Emailm.uzun@marmara.edu.tr

Received: November 20, 2017 | Published: January 29, 2018

\section{Introduction}

\section{A brief history of wound management}

A considerable amount of literature has been published on the ancient medical and wound management practices. These studies show that the first written historical record was found on Sumerian clay, which is the world's oldest medical manuscript. The "three healing gestures" explained in this manuscript were:

a. Washing the wound

b. Applying dressings

c. Bandaging the wound. ${ }^{1}$

Other important developments were carried out during the Egyptian civilisation. They made a great progress on primary human infections and inflammation control in ancient times. 2 Linen based textile gauze structure was employed as the wound dressing at that time. Preliminary work on honey, gums, resins and herbal extracts in woundcare application was undertaken by the Egyptians and the linen textile structures were coated with honey to make them antimicrobial. $^{3-5}$

The contribution of ancient Greeks to medical and wound management has also been highlighted by many historians. In order to identify the severity of wounds, the Greeks divided the wounds into two groups, based on infected nonhealing and noninfected healing wounds. Both Hippocrates \& Galen ${ }^{6}$ recognised the two types of wounds, the first one is dry and clean, which is healed by the first intention, and the other one is dirty which requires drainage before healing took place. Galen ${ }^{7,6}$ also suggested "laudable pus" theory. In another major study in ancient Greek, some metal powder, milk, honey, and wine were utilised in the gauze application for the first time. It was suggested that the metallic copper, when combined with vinegar, produced copper acetate, which had antibacterial properties, could help in the treatment of wounds and cutaneous ulcers. ${ }^{8}$

In the nineteenth century, a large variety of textile fibres (such as cotton, silk and wool) and structures (knitted, nonwoven and composites) were put into service as traditional wound dressing materials. The cotton gauze impregnated with paraffin as a wound dressing was developed by Lumerie in France. ${ }^{9}$ In the middle of the nineteenth century, the identification of bacteria and the use of antibiotics in the wound and wound healing took place. Semmelweis' $\mathrm{s}^{10}$ observations on the bacteria and antibiotics were followed by Pasteur and Joseph Lister during this process. In order to prevent the contamination of wounds, Lister ${ }^{10}$ began to wrap the wounds in many layers of gauze which is an important layer in a composite dressing. He placed a layer of relatively impermeable silk between the gauze layers and the wounds to prevent damage to the tissues by carbolic acid. The "germ free" wound environment theory was produced by Pasteur. Another noteworthy finding from his study was that the body fluid/exudate could not generate bacteria or infections. He suggested that the wound could be protected from environmentally infectious agents by covering and keeping it dry. ${ }^{11}$ Following Pasteur's discoveries, Koch ${ }^{12}$ noted that there was a major transfer of bacteria during surgery or treatment from the surgeon's hands, the instruments and bandages, as well as from the patients.

A milestone in the history of woundcare was carried out by Winter. He presented a model (Figure 1) that changed the traditional concept of wound healing. He discovered that keeping the wound environment moist would enhance healing and come up with much better clinical results as it was compared to keeping the wound environment dry. ${ }^{13}$ In recent times, the developments in cellular and molecular biology have greatly expanded and enhanced the current understanding of the biological processes involved in wound healing and tissue regeneration. A remarkable progress has been achieved and an ever-growing number of woundcare products have been designed and developed to incorporate the latest understanding of cellular and molecular level phenomena involved in the dynamic and complex process of wound healing, including blood coagulation, inflammation, fibroplasias, collagen deposition, and wound contraction. ${ }^{14}$ The primary goals of innovations are to alleviate patient suffering, to shorten wound healing time periods, and to resolve chronic wound healing clinical problems. The investigation and innovation of novel wound dressing materials and methods are an important part of the rapidly growing biomaterials industry throughout the world. ${ }^{15-17}$ 


\section{Wound kept moist by covering}

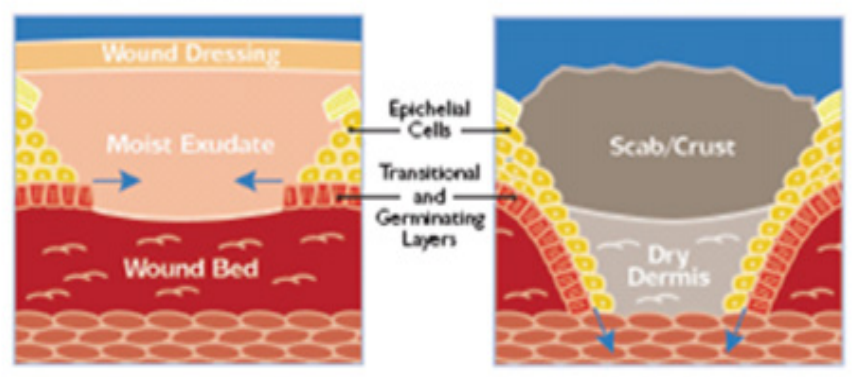

\section{- No deterrent to epithelial cells travelling across base of wound \\ - Epithelial cells move effortlessly across moist dermal surface \\ - Wound heals faster and without a scab}

\section{- Dermis dries out and forms scab/crust that impedes epithelial cell migration \\ - Epichelial cells must travel furcher to repair wound site \\ - Scabs fall off causing scarring or reinjury}

Figure I Moist Wound Healing Model.

An appropriate material has to be used to cover the wound in order to effectively heal the wound and to prevent it from any infectious agent. The main functions of the wound dressings are to avoid strikethrough and protect the wound areas from contamination and further injuries on the same wound area. A number of investigations have been conducted on wound-moist interactions and the results have indicated that if a wound is kept in moist conditions, it heals much faster than that in dry conditions. ${ }^{15,18-20}$ The search for the ideal dressing is ongoing with no currently available dressing that suits all patients or all wound types and at all stages of the healing process. The key requirements of wound dressings are given below:

i. Fluid control: the ability to absorb fluid, to donate water to a dry wound.

ii. Physical barrier: to avoid strikethrough, further physical damages.

iii. Microbial control: for infected wounds.

iv. Odour management: a wound often produces unpleasant and obnoxious odour.

v. Low adherences: good dressings can help eliminate adherence to a wound.

vi. Space filler: for deep cavity wounds.

vii. Debridement: by providing the appropriate moisture, temperature and $\mathrm{pH}$.

viii. Haemostatic: bleeding is stopped as early as possible to prevent blood loss.

ix. Scar reduction: scar formation presents a major aesthetic problem for the patient.

x. Metal ion metabolism: deficiency in any metal ion delays wound healing.

xi. Wound healing acceleration.

\section{Medical textiles}

Technical textiles are unique engineered structures offering superior solutions for an increasingly wide range of applications. Medical textiles are one of the most significant sectors in technical textiles and it has a broad spectrum of commercially available products such as wound dressings, sutures, bandages, scaffolds, masks, surgical gowns, etc. ${ }^{21}$ The use of nonwoven fabrics in medical textiles provides essential features such as high absorption, porosity, versatility in the sense of bulk and area densities. Most of the nonwoven medical products are single-use and disposable $(\sim 70 \%)$. Nonwoven fabrics are also commonly employed to produce composites because they possess light weight, flexibility, higher blending options, and high strength. ${ }^{22}$

Wounds are complex in nature and there is no universal single dressing to treat all types of wounds. The selection of the most proper wound dressing for a specific wound requires specialist knowledge as well as clinical assessment; however, the most fitting dressing for wound management depends not only on the type of wound but also on the stage of the healing process. ${ }^{23}$ Wound dressings are costly to the total annual healthcare budget of many developed countries. The market potential for healthcare and medical textiles is considerably increasing. It has been predicted that there is a substantial market potential for advanced wound dressings. The forecast for annual growth would be between $10 \%$ and $15 \%$ in $2012 .{ }^{24}$ In the US alone there are over 100,000 surgeries performed daily involving surgical wounds. Ageing population creates increased demands for all types of surgical intervention, particularly cardiovascular, orthopaedic, urological and dermatological procedures. The treatment of venous leg ulcer generates considerable demands on healthcare professionals throughout the world. In the UK alone the treatment of this condition costs the NHS of $£ 650$ million per year. ${ }^{25}$

Some of the major requirements from a wound dressing are to; alleviate pain, absorb exudates, prevent infection and contaminant contact with wound, sustain non-toxicity, moist environment, optimum gaseous permeability, temperature, and $\mathrm{pH}$. There are also a great number of desirable properties expected from a modern wound dressing, including biodegradability, bioabsorbability, and ease of application, flexible, comfortable, and impermeable to bacteria. ${ }^{26}$ Antibacterial property is one of the most frequently desired properties from a wound dressing, wherein the growth of microorganisms is controlled/eliminated by the presence of antimicrobial agents that are imbued into the fibre structure. Nowadays nonwoven fibrous wound dressings are being used more commonly in the management of highly exuding wounds. Carboxyl methylcellulose (CMC) and alginate fibres are the two most frequently used smart and bioactive fibres in high absorbent wound dressing applications in which they have considerable scientific and commercial attraction. PLA fibre is one of the fastest growing biodegradable fibre types in the current investigations where researchers are actively endeavouring to introduce novel application areas as an alternative source to conventional synthetic fibres ${ }^{27}$ PLA has also some biomedical applications, such as sutures, scaffolds for tissue engineering and drug delivery systems. ${ }^{28,29}$

\section{Wound management materials}

As briefly discussed above, wound dressing materials can play a vital role in wound healing management. An ideal wound dressing does not only act as a physical barrier for wound against mechanical trauma but also accelerate the healing process and prevent bacterial infection. In this regard, the development of wound dressings can be 
discussed taking account of traditional and modern (advanced, smart) dressings into consideration.

The basic characteristics and properties of the traditional wound dressings are: keeping wounds dry and warm; avoiding strikethrough; absorbent pad; and a physical barrier such as gauzes and felt. The adherence structure of the traditional dressings is one of the biggest problems which causes real trauma to patients due to their difficulty to remove from the wound surface. Recently, there has been an increasing interest in the development low adherence traditional dressings such as adding polyamide contact layer, the coating viscose fibre with polypropylene (PP), the impregnating paraffin onto the gauze. Even though there are newer developments in the traditional dressings, still they do not possess enough properties for the complex wound healing applications. Instances of widely used traditional dressings for the wound management are: extensible bandages, cotton and rubber elastic bandages, elastic adhesive bandages, elastic web bandages, extension strapping, heavy cotton and rubber elastic, titanium dioxide elastic adhesive bandages and ventilated elastic bandages. . $^{15,21,30,31}$

It is well-known that during the wound healing process, wound dressings protects the injury and contributes to the recovery of dermal and epidermal tissues. For such reasons, natural polymers such as polysaccharides and derivatives (e.g., carboxymethlycellulose, alginates, chitosan and heparin), proteoglycans and proteins (e.g., collagen, gelatine, fibrin, and keratin) are widely employed to develop modern wound management dressings. Their common properties are suitable biodegradability, biocompatibility and similarity to macromolecules that are usually recognised by the human body ${ }^{32}$ Some of the current modern (advanced) wound dressings' materials and structures are discussed below:

Hydrocolloid wound dressings: Hydrocolloid dressings are among the most widely used modern dressings and they are a type of dressing containing gel-forming agents such as sodium carboxymethylcellulose $(\mathrm{NaCMC})$, gelatine, pectin, and alginate. Once they contact with wound exudate, these polymers absorb exudate and then swell. The hydrocolloid dressings have essential properties for wound dressing applications including a good performance against bacteria. As they are occlusive, hydrocolloid dressings do not allow water, oxygen, or bacteria to enter into the wound. This may help facilitate angiogenesis and granulation. Hydrocolloids also cause the $\mathrm{pH}$ of the wound surface to drop; the acidic environment can inhibit bacteria growth. ${ }^{33}$ Another important benefit of the hydrocolloid wound dressings is conformable to the patient's body and adheres well to high-friction areas, such as the sacrum and heels.

Foams/semi-permeable films: The foams are porous materials having both flexibility and high absorption capacity. Semi-permeable film is sterile sheet of polyurethane coated with acrylic adhesive. It is used to produce a sterile field through which to make surgical incisions, some more sophisticated films are manufactured with differing moisture/ vapour permeability and, are used for venous access sites. They can be put to use as a primary secondary dressing. Some of the commercially available foam dressings are Silastic, Lyofoam, Tegaderm, HyperFoam, and Shingna. They conform easily to the patient's body. As films are transparent, the wound can be easily monitored. Due to their film structure, they are semi occlusive and trap moisture; they allow autolytic debridement of necrotic wounds and create a moist healing environment for granulating wounds.

Hydrogel wound dressings: Hydrogels are cross-linked polymeric networks swollen in biological fluid and are widely put into service in drug delivery and tissue/organ repairs. Hydrogel dressings are water or glycerine-based products. CMC, agar, glycerol and pectin can be used for hydrogel wound dressing production. Hydrogel polymers can absorb $30-90 \%$ or more of its mass in water. The hydrogel dressings are useful for dermabrasion, minor burns and skin donor sites. Hydrogels maintain a moist wound environment on a clean, healthy, granulating wound, and to facilitate autolytic debridement in wounds with necrotic tissue such as slough or eschar.

Composite wound dressings: The wound healing has a number of stages due to this there is a need for a multi-functional wound dressing that could be effective in each stage of the healing process on account of this. The development of composite dressings is aimed to combine different materials for the complex clinical requirements and applications. An example of a composite dressing is the postoperative jubilee dressing (Aquace ${ }^{\circledR}$ Surgical) which consists of a hydrofibre inner layer with a viscoelastic hydrocolloid outer layer, and is designed as a composite dressing for post-surgical applications such as following a total knee replacement procedure. ${ }^{34}$

Nanofiber based wound dressings: Recent studies indicate that nanofiber wound dressings have great potential for both acute and chronic wound healing. Nanofiber-based wound dressings obtained from synthetic or natural polymers have unique properties such as high surface area, volume ratio, 3-D micro porous structure, ${ }^{35}$ high porosity and permeability. ${ }^{36}$ These could help to increase the ability to mimic the extracellular matrix (ECM). There are limited studies about long-term stability of nanofibers. Tort et al have tried to combine the benefits of collagen, chitosan and alginate in their recent study and they showed that the combination could accelerate healing as the structure produced as nanofibers. ${ }^{37}$

3-Dimensional (3D) printed wound dressings: A wound may require the application of an external dressing to temporarily compensate for the damaged barrier and to allow healing to initiate and progress. In this perspective, dressing has to cover wound area as much as possible to isolate the injury site from the external environment; however, some body parts such as ear, nose, and chin etc., needs customised shapes for providing optimal environment. 3D scanning is used to construct 3D models of such body parts to provide the opportunity to customize shape and size of wound dressing to an individual patient. ${ }^{38}$

Alginate wound dressings: Generally, it is a primary dressing for the management of heavily exuding wounds, including chronic leg ulcers, pressure ulcers, fungating carcinomas and acute wound such as abrasions, lacerations and post-surgical wounds. AlgiDERO, AlgiSite, CarraSorb, Kaltostat and SorbSan are some of the commercial alginate wound dressings. Alginates are mainly obtained from brown sea algae such as Macrocystis pyrifera, Laminaria hyperborean, Sargassum, Durvillaea Antarctica, Ecklonia maxima, Lessonia nigrescens and Ascophyllum nodosum. ${ }^{39-42}$ This polysaccharide was first discovered and patented as an impure alginate salt in 1880 s by E.C.Standford, ${ }^{40,43,44}$ but later, in the 1950s, it was used for biotechnology applications. Alginate fibers have some superior inherent features such as high absorbency, biodegradability, gelling and biocompatibility properties. Being from the family of unbranched binary copolymers, alginates consist of $(1 \rightarrow 4)$ linked $\beta$-D- mannuronic acid $(\mathrm{M})$ and $\alpha$-L-guluronic acid $(G)$ residues (Figure 2) of widely varying composition and sequence. ${ }^{45}$ It was found that alginate could be regarded as a true block copolymer composed of homopolymeric regions of M- and G- blocks, respectively, interspersed with regions of alternating 
structure ${ }^{46,47}$ The proportion of $\mathrm{M}$ to $\mathrm{G}$ units and their arrangements in each polymer vary with the source of algae, which in turn affects the physical strength and other physical properties of the polymer. ${ }^{40,48,49}$ The calcium ions present in high-M alginates are less firmly attached to the molecules than those in high-G alginates, and as a result, are more easily replaced by sodium ions. This increases fluid uptake and swelling speed of the alginate fibers. Hydroxyl groups in each alginate molecule contribute to its hydrophilicity and it is well-known that alginates swell when in contact with fluids. On contact with wound exudates, an ion exchange reaction takes place between the calcium ions in the dressing and sodium ions in wound exudates. Once significant ratio of the calcium ions present in the fiber have been replaced by sodium, the fiber swells and partly dissolves. The degree of swelling depends on its botanical source which gives the chemical composition of the alginate. It is particularly used in wound dressing applications owing to its high absorbency of exudates. ${ }^{50}$ When alginate dressing comes into contact with the wound exudates, it absorbs the exudates and provides a desirable wound moist environment thanks to its gel forming property ${ }^{51}$ and also allows adequate exchange of water vapour and oxygen which is an important property for enhancing the wound healing and the moisture environment leads to rapid granulation and reepithelialisation. ${ }^{50,52}$

a)

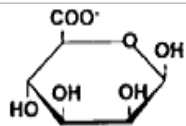

$\beta-D-m$ annuronate $(M)$

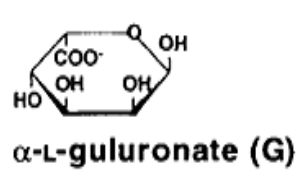

b)

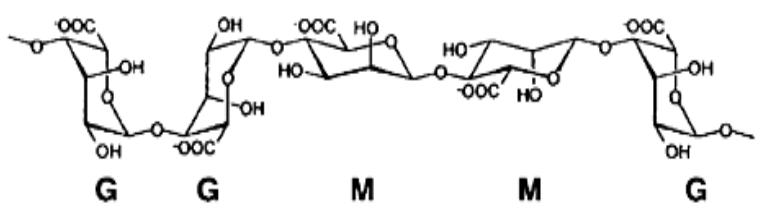

c)

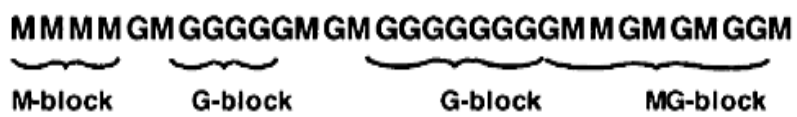

Figure 2 Structural characteristics of alginates: (a) alginate monomers, (b) chain conformation, (c) block distribution. ${ }^{58}$

The gelling property of alginate also helps for painless removal of the dressings. Alginate can absorb 15 to 20 times its weight of fluid and therefore moderate to heavy exudates be addressed with alginate dressings. ${ }^{53}$ Alginate dressings have been demonstrated to activate human macrophages to secrete pro-inflammatory cytokines associated with accelerated healing. ${ }^{54}$ When alginate is used in medical purposes, it is necessary to go through some additional purification steps. These include the mechanical washing of the stems of the seaweed and eliminating endotoxins and protein by chemical and physical methods ${ }^{55} \mathrm{~A}$ large and growing volume of literature have highlighted the applications of alginate in wound dressings including its use in the management of dehisced surgical abdominal wounds, leg ulcers, toxic epidermal necrolysis, burns and donor sites, pressure ulcers, footcare applications and cavity wounds..$^{56}$ Alginate has been strived to be combined with other textile fibers such as cotton and chitosan. Edward et al. ${ }^{57}$ studied the combination of cotton and alginate in a dressing material. They have sought to integrate the properties of cotton and alginate into a single dressing.
Alginate is highly biocompatible and has very interesting features such as being non-toxic, non-irritant, ease of use and mix, enhanced absorbency and swelling; however, some of disadvantages of alginate are poor dimensional stability and is messy to work with. ${ }^{58}$ Preliminary work on alginate fiber spinning process was undertaken by Speakman et al in 1939. The fiber processing is found to be easy and it is mainly based on exchange of sodium ions $\left(\mathrm{Na}^{+}\right)$present in the soluble sodium alginate and calcium ions $\left(\mathrm{Ca}^{+2}\right)$ present in the coagulating calcium chloride bath. ${ }^{40,59} \mathrm{Ca}^{+2}$ released from calcium alginate dressings are a crucial blood coagulation factor that exerts haemostatic effects on the wound. ${ }^{50}$

Hydrofibre wound dressings: Aquacel ${ }^{\mathrm{TM}}$ is a well-known hydrofibre containing dressing and was developed by ConvaTec Ltd, USA, in 1997. The dressings contain sodium carboxymethyl cellulose. This is a kind of hydrocolloid with higher absorbent properties which can absorb up to 25 times its own weight and they are also capable of a high degree of swelling. These are the most demanded properties for wound dressing applications. When the skin is broken, a large number of micro-organisms may grow on and/or in the wound. In this case, $\mathrm{CMC}$ wound dressings have the ability of absorbing large amounts of body fluids, thus removing a large volume of the exudate. This may lead to a decrease in the number of micro-organisms present on the wound surface. ${ }^{21,60}$ The CMC containing nonwoven dressing can retain the soft and comfortable feeling to the patient and provides an optimal performance for the wound healing due to its conformability and high water absorbency. CMC is also similar in appearance and gel forming properties to the alginates, offers similar benefits to a healing wound. $\mathrm{CMC}$ nonwoven dressing absorbs liquid when it comes into intimate contact with the liquid, but not via the usual mechanism of capillary action. Absorbed fluid is retained within the structure of the fibre even under compression. The lateral area wicking of fluid across the dressing is limited. As the dressing absorbs exudates it is rapidly converted from a dry dressing to soft coherent gel sheet. CMC fibre maintains a moist milieu for the optimal wound healing, aids autolysis debridement, and is easily removed with little or no damage to newly formed tissue. ${ }^{52}$

General applications of CMC dressings are chronic wounds such as leg ulcers, pressure ulcers and acute wounds such as abrasion, laceration, incision, donor sites, and first and second degree burns. The dressing is also intended for use in the management of surgical or traumatic wounds that have been left to heal by secondary intent. It is indicated for the local management of wounds that are prone to bleeding such as wounds that have been mechanically or surgically degraded, donor sites and traumatic wounds.

Polylactic acid (PLA): Polylactic acid (PLA) is linear aliphatic thermoplastic polyester derived from $100 \%$ renewable natural sources such as corn and crops, not like conventional synthetic polymers which rely on reserves of oil and gas. It possesses excellent properties including biocompatibility, compostability and low toxicity to humans. ${ }^{61-65}$ PLA fibre is one of the fastest growing biodegradable fibre types in the current investigations in which researchers are actively trying to introduce novel application areas as an alternative source to synthetic fibres. ${ }^{27}$ It is mostly used for biomedical implementations such as sutures, scaffolds and drug delivery systems. ${ }^{28,29,66}$ The polymer is compostable and is formed either by direct condensation of lactic acid or by the cyclic intermediate dimer through a ring opening process. The conventional melt spinning method can be used for processing PLA fibres. Carbon dioxide is removed from 
the atmosphere with composting of PLA. Tissue engineering also employs both natural and synthetic polymers electrospun into fibres such as PLA fibre. ${ }^{67,68}$

PLA fibre properties are similar to many other thermoplastic fibres such as low moisture regain and smooth surface. PLA has noteworthy commercial potential as a textile fibre. Its mechanical properties are found to be similar to the conventional PET and also its low melting and softening temperatures are similar to the polypropylene fibre. The specific gravity of PLA is lower than other natural fibres $\left(1.25 \mathrm{gcm}^{-3}\right)$. The tenacity at break $\left(32-36 \mathrm{cN} \mathrm{tex}^{-1}\right)$ is higher than for other natural fibres. PLA has an excellent wickability, fast fluid spreading, and rapid drying. ${ }^{29,69}$ PLA fibres do not have antimicrobial properties without suitable treatment. ${ }^{29,70}$ However, Ludwick et al. ${ }^{71}$ pointed out that PLA demonstrated a bacteriostatic effect against two common organisms cultured from draining ears after tympanostomy tube placement, $P$. aeruginosa and $S$. aureus. It has been suggested that the moisture management properties of PLA are an important consideration for next-to-skin applications. ${ }^{72,73}$ It has a higher natural hydrophilicity than most other thermoplastic polymers including polypropylene, polyamide and PET. PLA fibre has been utilised in the diaper and feminine hygiene markets due to its superior wicking properties. The elastic recovery and crimp retention properties of PLA provide enhanced shape retention and decreased resistance to textile structure. It has been used in filtration and separation applications to improve filtration efficiency and for single use applications. PLA is one of the major bioresorbable fibres used in implants. It can also be blended with different polymers and copolymers such as polyglycolic acid (PGA)..$^{74,75}$

The main benefit of using biodegradable and bioresorbable fibres is that no further surgery is required to remove the products because they slowly degrade and are ultimately absorbed by the tissues in the body without any side effects. ${ }^{76}$ Another application of PLA is orthopaedic applications such as bone support splints. ${ }^{77,78}$ PLA is widely used in surgery due to its improved mechanical strength, ${ }^{79-81}$ Cai et al ${ }^{82}$ found that PLA can make homogeneous composites and PLA scaffolds resist significantly higher stresses. The PLA waste can be processed using composting, chemical recycling and anaerobic digestion.

Polycaprolactone (PCL): In general, wound dressings are prepared from absorbent and cross-linked polymer networks. One present polymer is polycaprolactone (PCL), semi-crystalline polyester that is biodegradable and biocompatible. There are some PCL based drug-delivery devices and implants which are approved by FDA. A great number of studies have been investigated the act of applying of PCL on wound and burn dressings ${ }^{83}$ tissue engineering, scaffold manufacturing, drug targeting and 3D wound dressings (1-A). Muwaffak et al. ${ }^{38}$ have successfully developed 3D printed wound dressings in corporation with $\mathrm{Ag}, \mathrm{Cu}$, and $\mathrm{Zn}$ into PCL filaments by making use of hot melt extrusion.

\section{Conclusion}

Wound healing is a multi-phases and multi-factorial physiological process. The complexity of this phenomenon makes the healing process very difficult and painful due to several abnormalities. Apart from cellular and biochemical components, a number of external pathways also become active during repair and help the tissue to heal. Wound dressing is one of the main external effectors during the healing process of wounds. In this review, the main issues of the wound dressings have been highlighted.

\section{Acknowledgements}

None.

\section{Conflict of interest}

Author declares there is no conflict of interest in publishing the article.

\section{References}

1. Majno G. The Healing Hand: Man and Wound in the Ancient World. Cambridge: Harvard University Press; 1975. p. 600.

2. Nicholson PT, Ian S. Ancient Egyptian Materials and Technology. Cambridge: Cambridge University Press; 2000. p. 1-19.

3. Majno G. The Swnw (Egypt): The Healing Han. Man and Wound in the Ancient World. Massachusetts: Harvard University Press; 1975. p. 571.

4. Wang T, Xiao-Kang Z, Xu-Ting X, et al. Hydrogel sheets of chitosan, honey and gelatin as burn wound dressings. Carbohydrate Polymers. 2012;88(1):75-83.

5. Meri JW. Medieval Islamic Civilization: An Encyclopaedia. UK: Routledge; 2006. p. 300

6. Dealey C. Wound healing in Moorish Spain. EWMA Journal. 2002;34:32-34.

7. Gorbach SL. Good and Laudable Pus. J Clin Invest. 1995;96(6):2545.

8. Caldwell MD. Topical wound therapy-an historical perspective. J Trauma. 1990;30(12 Suppl):116-122.

9. Cavendish M. Inventors and inventions. Marshall Cavendish Coorp, New York; 2007.

10. Savin JA. Joseph Lister: a neglected master of investigative dermatology. Br J Dermatol. 1995;132(6):1003-1007.

11. Lawrence G. Surgery (traditional). In: Bynum WF, Companion Encyclopedia of the History of Medicine. London, New York: Routledge, 1993;2:961-983.

12. Wells TS. Some cause of excessive mortality after surgical operations. British Medical J. 1864;196(2):384-388.

13. Bryan J. Moist wound healing: a concept that changed our practice. $J$ Wound Care. 2004;13(6):227-228.

14. Lee YH, Chang JJ, Yang MC, et al. Acceleration of wound healing in diabetic rats by layered hydrogel dressing. Carbohydrate Polymers. 2012;88(3):809-819.

15. Dee KC, Puleo DA Bizios R. An introduction to Tissue-Biomaterial Interactions. New York: Wiley \& Sons; 2002.

16. Zahedi P. A Review on Wound Dressings with an Emphasis on Electronicspun Nanofibrous Polymeric Bandages. Polymer Advanced Technologies. 2010;21(2):77-95.

17. Qin Y. Advanced wound dressings. $J$ Textile Institute. 2001;92(2):127-138.

18. Bolton LL, Monte K, Pirone LA. Moisture and Healing: Beyond the Jargon. Ostomy Wound Manage. 2000;46(1A Suppl):51S-62S.

19. Mabrouk A. Moist occlusive dressing (AquacelW Ag) versus moist open dressing (MEBOW) in the management of partial-thickness facial burns: A comparative study in Ain Shams University. Burns. 2012;38(3):396-403.

20. Morton LM, Phillips TJ. Wound Healing Update. Semin Cutan Med Surg. 2012;31(1):33-37. 
21. Anand SC, Kennedy JF, Miraftab M, et al. Medical textiles and biomaterials for healthcare. Cambridge: Woodhead publishing; 2006. p. 499-508.

22. Ajmeri JR, Ajmeri CJ. Nonwoven materials and technologies for medical applications. In: Bartels VT, editor. Handbook of medical textiles. Cambridge: Woodhead Publishing; 2001. p. 106-131.

23. Bentley J. Understanding the wound healing process. Practice Nursing. 2004;15(4):181-188.

24. Rajendran S, Anand SC. Woven textiles for medical applications. In Gandhi K, editor. Woven textiles: Principles, technologies and applications. Cambridge: Woodhead Publishing; 2012. p. 414-441.

25. Morrell CJ. Cost effectiveness of community leg ulcer clinics: randomised controlled trial. British Medical J. 1998;316:1487.

26. London AP, Tonelli AE, Hudson SM, et al. Textile composite wound dressing. IEEE. USA; 1995.

27. Amass AJ, N Goala KLR, Tighe BJ, et al. Polylactic acids produced from 1- and dl-lactic acid anhydrosulfite: stereochemical aspects. Polymer. 1999;40(18):5073-5078.

28. Lunt J. Polylactic Acid Polymers for Fibers and Nonwovens. International Fiber J. 2000;55:48-52.

29. Farrington DW. Poly (lactic acid) fibers. In: Blackburn RS, editor. Biodegradable and sustainable fibres. Cambridge: Woodhead Publishing; 2005 .

30. Anand SC. Medical textiles 96. Cambridge: Woodhead Ltd; 1997. p. 149.

31. Menaker GM. Wound Dressings at the Turn of the Millennium. Curr Problem Dermato. 2001;13(2):86-89.

32. Capanemaa SVN, Mansura AAP, Jesusa A, et al. Superabsorbent crosslinked carboxymethyl cellulose-PEG hydrogelsfor potential wound dressing applications. International J Biological Macromolecules. 2017;106:1218-1234.

33. Vowden K, Vowden P. Wound dressings: principles and practice. Surgery. 2017;29(10):491-495.

34. Burke NG, Green C, McHugh G, et al. A prospective randomised study comparing the jubilee dressing method to a standard adhesive dressing for total hip and knee replacements. $J$ Tissue Viability. 2012;21(3):8487.

35. Natu MV, De Sousa HC, Gil MH. Effects of drug solubility, state and loading on controlled release in bicomponent electrospun fibers. Int $J$ Pharm. 2010;397(1-2):50-58.

36. Aduba DC, Hammer JA, Yuan Q, et al. Semi-interpenetrating network (sIPN) gelatin nanofiber scaffolds for oral mucosal drug delivery. Acta Biomater. 2013;9(5):6576-6584.

37. Tort S, Acartürk F, Beşikci A. Evaluation of Three-layered Doxycycline-collagen Loaded Nanofiber Wound Dressing. Int J Pharm. 2017;529(1-2):642-653.

38. Muwaffak Z, Goyanes A, Clark V, et al. Patient-specific 3D scanned and $3 \mathrm{D}$ printed antimicrobial polycaprolactone wound dresings. Int $J$ Pharm. 2017;527(1-2):161-170.

39. Goh CH, Heng PWS, Chan LW. Alginates as a useful natural polymer for microencapsulation and therapeutic applications. Carbohydrate Polymers. 2012;88(1):1-12.

40. Wee S, Gombotz WR. Protein release from alginate matrices. Adv Drug Deliv Rev. 1998;31(3):267-285.
41. Andersen IL, Skipnes O, Smidsrød O, et al. Some biological functions of matrix components in benthic algae in relation to their chemistry and the composition of seawter. ACS Symp Ser. 1977;48:361-381.

42. Thu HE, Zulfakar MH, Ng SF. Alginate based bilayer hydrocolloid films as potential slow-release modern wound dressing. Int J Pharm. 2012;434(1-2):375-383

43. Chapman DJ. Algin and alginates. Seaweeds and their uses. New York: Chapman and Hall; 1980.

44. Stanford EC. Alginate. British Pat. No. 142, UK; 1881.

45. Draget KI, Smidsrod O, Break GS. Alginates from algae. In: Steinbuchel A, Rhee SK, editors. Polysaccharides and polyamides in the food industry, Production and patenrs. Germany: Wiley-VCH, Weinheim; 2005. p. 771.

46. Painter TJ, Smidsrod O, Haug A. A computer study of the changes in composition distribution occurring durng random depolymerisation of a binary linear heteropolysaccharide. Acta Chem Scand. 1968;22(5):1637-1648.

47. Larsen B, Olav S, Terence P, et al. Calculation of th nearest-neighbour frequencies in fragments of alginate from the yields of free monomers after partial hydrolsis. Acta Chem Scand. 1970;24(2):726-728.

48. Gaserod O, Smidsrod O, Skjak-Braek G. Microcapsules of alginate-chitosan-I. A quantitative study of the interaction between alginate and chitosan. Biomaterials Cilt. 1998;19(20):1815-1825.

49. Lee YH, Chang JJ, Yang MC, et al. Acceleration of wound healing in diabetic rats by layered hydrogel dressing. Carbohydrate Polymers. 2012;88(3):809-819.

50. Lloyd LL, Kennedya JF, Methacanona P, et al. Carbohydrate polymers as wound management aids. Carbohydrate Polymers. 1998;37(3):315-322.

51. Morgan DA. Wound management products in the Drug Tariff. The Pharmaceutical Journal. 1999;7072:820-825.

52. Williams C. Algosteril calcium alginate dressing for moderate/high exudate. Br J Nurs. 1999;8(5):313-317.

53. Bello YM, Philips TJ. Recent advance in wound healing. JAMA 2000;283(6):716-718

54. Thomas A, Harding KG, Moore K. Alginates from wound dressings activate human macrophages to secrete tumor necrosis factor- $\alpha$. Biomaterials. 2000;21(17):1797-1802.

55. Dusseault J, Tam SK, Ménard M, et al. Evaluation of alginate purification methods: effect on polyphenol, endotoxin and protein contamination. J Biomed Mater Res A. 2006;76(2):243-251.

56. Thomas S. Wound Dressings. In: Rovee TD, Maibach HI, editors. The Epidermis in wound healing. CRC Press LLC, New York, USA; 2004. p. 408.

57. Edwards JV, Bopp AF, Batiste SL, et al. Human neutrophil elastase Inhibition with a novel cotton-alginate wound dressing formulation. $J$ Biomed Mater Res. 2003;66(3):433-440.

58. Draget KI, Taylor C. Chemical, physical and biological properties of alginates and their biomedical implications. Food Hydrocolloids. 2011;25(2):251-256.

59. Thomas S. Alginate dressing in surgery and wound management. $J$ Wound Care. 2000;9(2):56-60.

60. Duteille F, Jeffery SL. A phase II prospective, non-comparative assessment of a new silver sodium carboxymethylcellulose (AQUACELW Ag BURN) glove in the management of partial thickness hand burns. Burns. 2012;38(7):1041-1050. 
61. Jung YK, Lee SY. Efficient production of polylactic acid and its copolymers by metabolically engineered Escherichia coli. J Biotechnol. 2011;151(1):94-101.

62. Mehta R, Vineet K, Haripada B, et al. Synthesis of poly (lactic acid): a review. J Macromol Sci Polym Rev. 2005;45(4):325-349.

63. Vink ETH, Rábago KR, Glassner DA, et al. Applications of life cycle assessment to NatureWorksTM polylactide (PLA) production. Polym Degrad Stab. 2003;80(3):403-419.

64. Kolstad JJ, Vink ETH, Wilde BD, et al. Assessment of anaerobic degradation of Ingeo polylactides under accelerated landfill conditions. Polymer Degradation \& Stability. 2012;97(7):1131-1141.

65. Goycoolea MV, Muchow DC, Sirvio LM, et al. In search of missing links in otology. II. Development of an implantable middle ear drug delivery system: initial studies $\mathrm{f}$ the sustained ampicillin release for the treatment of otitis media. Laryngoscope. 1991;101(7):727-732.

66. Pitarresi. Electrospinning of a,b-poly(N-2-hydroxyethyl)-DL-aspartamidegraft-polylactic acid to Produce a Fibrillar Scaffold. Macromolecular Nanotechnology. 2010;46(2):181-184.

67. Edwards JW, Diller GB, Goheen C. Modified fibers with medical and specialty applications. Springer, Dordrecht, Netherlands; 2005.

68. Li Y, Chen F, Nie J, et al. Electrospun poly(lactic acid)/chitosan coreshell structure nanofibers from homogeneous solution. Carbohydrate Polymers. 2012;90(4):1445-1451.

69. Mang M. Poly (lactic acid): Performance Materials from Renewable Resources. NPE 2000 Conference, Chicago, USA; 2000.

70. Mascheroni E, Guillard V, Nalin F, et al. Diffusivity of propolis compounds in Polylactic acid polymer for the development of anti-microbial packaging films. J Food Engineering Cilt. 2010;98(3):294-301.

71. Ludwick JJ, Rossmann SN, Johnson MM, et al. The bacteriostatic properties of ear tubes made of absorbable polylactic acid. Int J Pediatr Otorhinolaryngol. 2006;70(3):407-410.

72. Avérous L. Polylactic Acid: Synthesis, Properties and Applications. In Belgacem MN, Gandini A, editors. Monomers, Polymers and Composites from Renewable Resources. Elsevier Ltd, Amsterdam, Netherlands; 2008. p. 433-450.
73. Comparison of physiological comfort of polyester (PET)/cotton and NatureWorks $^{\mathrm{TM}}$ fibers/cotton fabrics. Forschungsinstitut Hohenstein, Hohenstein, Germany; 2000.

74. Ahn HK. Biodegradability of injection molded bioplastic pots containing polylactic acid and poultry feather fiber. Bioresource Technology. 2011;102(7):4930-4933.

75. Palumbo FS. New graft copolymers of hyaluronic acid and polylactic acid: Synthesis and characterization. Carbohydrate Polymers. 2006;66(3):379-385.

76. Sagala HF, Kubera Sampath Kumar S, Subramanian S, et al. PLA (polylactic acid) nanofibers for medical application. Arena Tekstil 2009;24(2):94-101.

77. Viju S, Thilagavathi G. Recent developments in PLA fibers. Chemical Fibers International. 2009;59:152-153.

78. Zhou H, Lawrence JG, Bhaduri SB. Fabrication aspects of PLA-CaP/ PLGA-CaP composites for orthopedic applications. Acta Biomater. 2012;8(6):1999-2016.

79. Shen XY, Tong H, Zhu Z, et al. A novel approach of homogenous inorganic/organic composites through in situ precipitation in poly-acrylic acid gel. Mater Lett. 2007;61(3):629-634.

80. Shen XY, Tong H, Jiang T, et al. Homogeneous chitosan/carbonate apatite/citric acid nanocomposites prepared through a novel in situ precipitation method. Compos Sci Technol. 2007;67(11-12):2238-2245.

81. Bolay NL, Santran V, Dechambre G, et al. Production, by co-grinding in a media mill, of porous biodegradable polylactic acid-apatite composite materials for bone tissue engineering. Powder Technology. 2009;190(1-2):89-94.

82. Cai X, Tong H, Shen X, et al. Preparation and characterization of homogeneous chitosan-polylactic acid/hydroxyapatite nanocomposite for bone tissue engineering and evaluation of its mechanical properties. Acta Biomaterialia. 2009;5(7):2693-2703.

83. Boateng J, Catanzano O. Advanced therapeutic dressings for effective wound. J Pharm Sci. 2015;104(11):3653-3680. 